ISSN 1991- 8690

website: http://jsci.utq.edu.iq

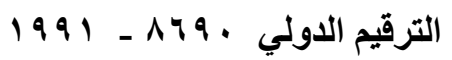

Email: utjsci@utq.edu.iq

\title{
استخدام معطيات التحسس النائي لرصد التغيرات البيئية لاهوار جنوب العراق علي فاضل حسن النائلي
}

كلية الزراعة - جامعة المثىـ قسم الانتاج النباتي

\section{الخلاصة}

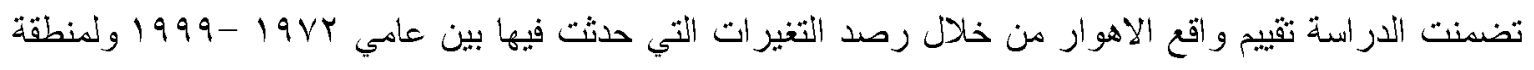

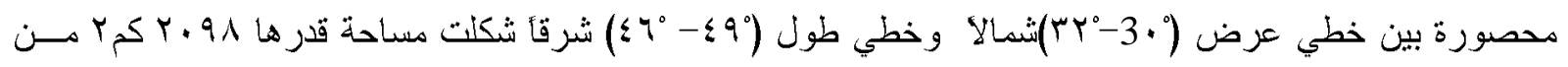
خلال اعداد خر ائط غرضية بالاعتماد على ثلاث مرئيات فضائية ملونة كاذبة للقمر الاصطناعي الاميركي

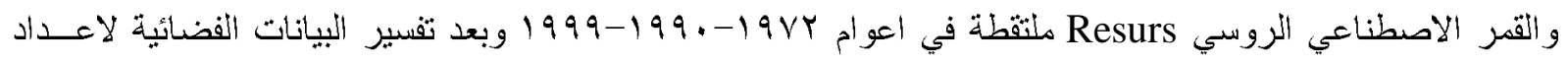
خر ائط غرضية لاصناف استخدامات الارض و النطاء الارضي بالاعتماد على نظــام 1976 مارسيا Anderson

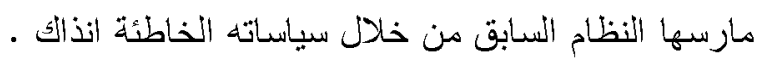

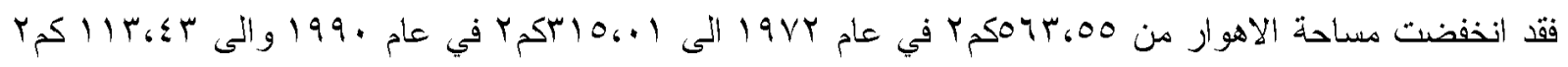

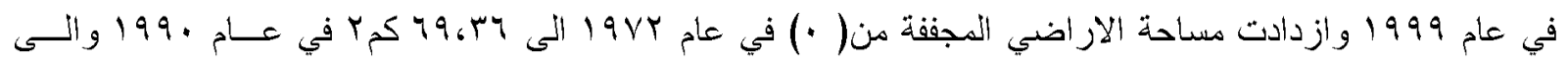

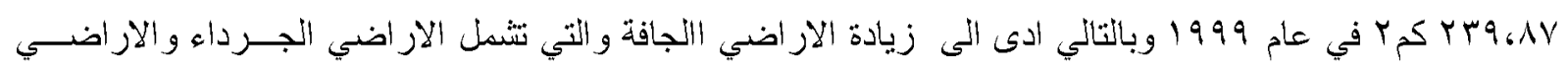

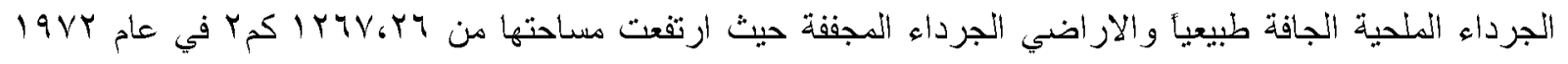

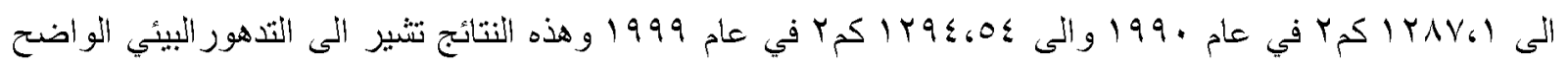

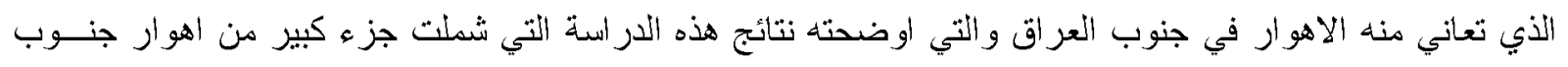
العراق. 


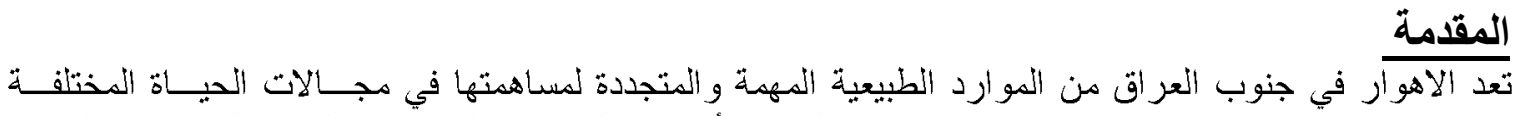

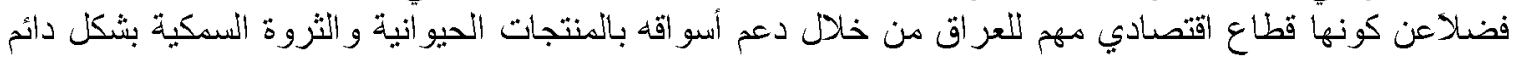

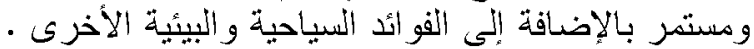
ونظر أ إلى التغير ات التي مر بها العر اق في العقود المنصرمة فقد عانت الأهو ار من مشاكل عده أهمها عمليـات

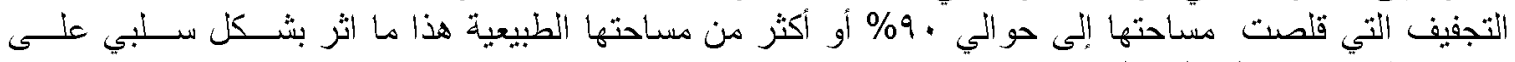
و اقعها وثرو اتها بشكل ملحوظ.

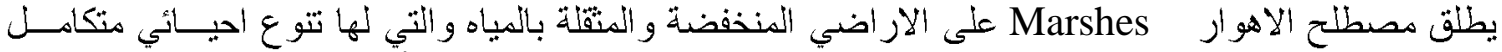

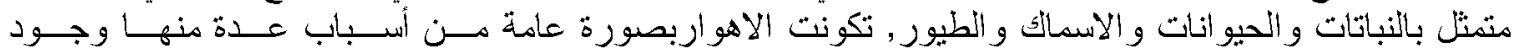

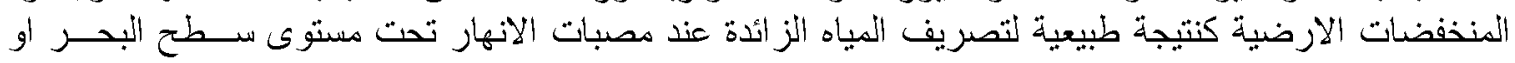

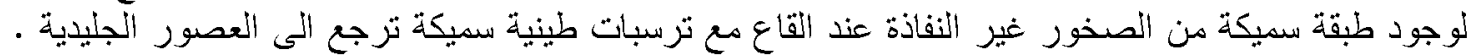

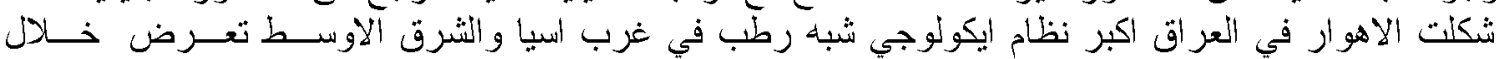

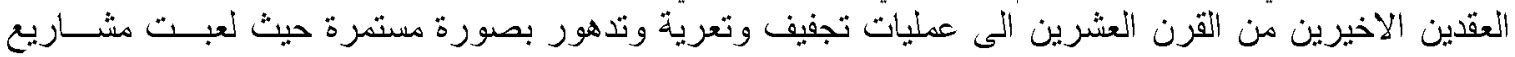

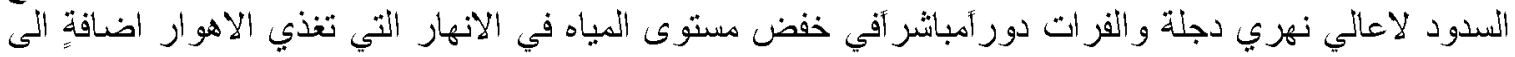

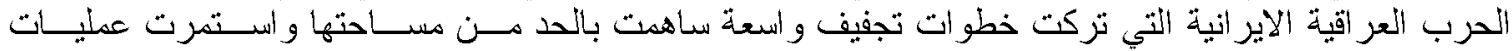

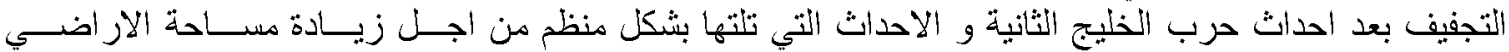

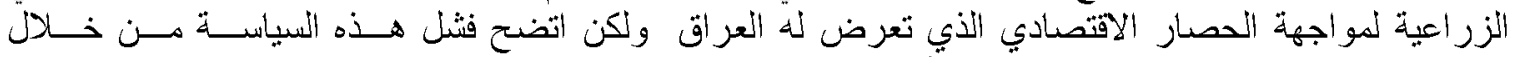

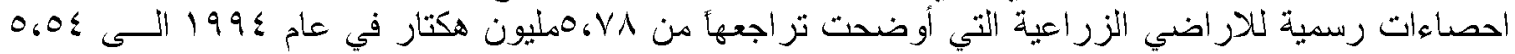

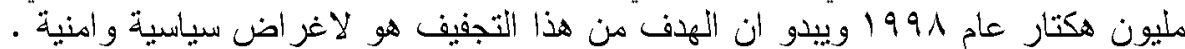

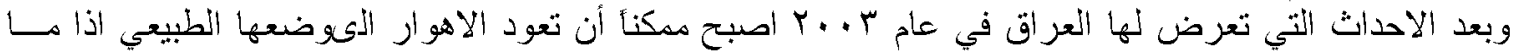

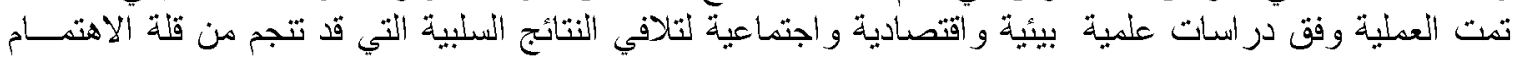

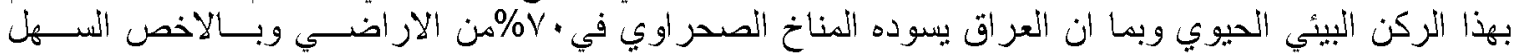

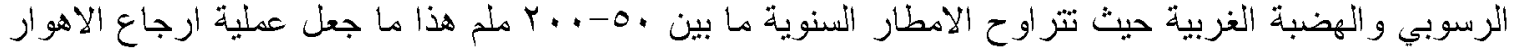
الى وضعها الطبيعي امراً صعباً.

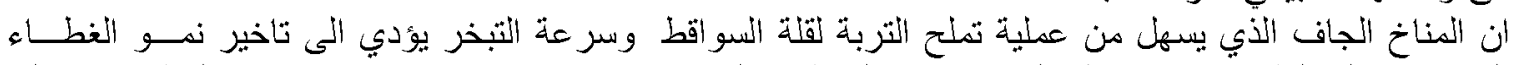

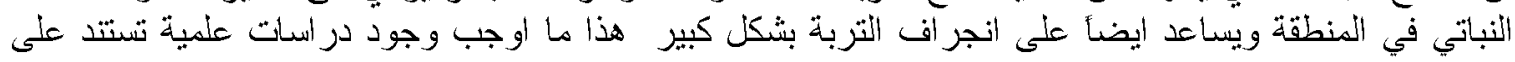
اسس متينة لوضع حلول جذرية لهذه المشاكل لارجاع الاهو ار الى سابق عهدها وتعد بيانات الاقمار الاصنية الصناعية

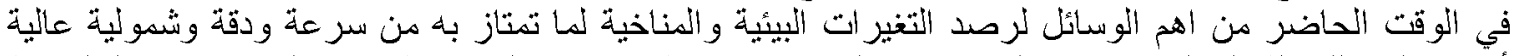

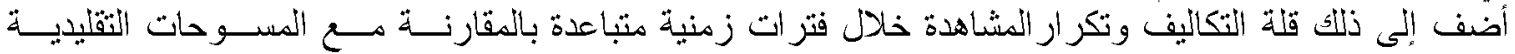

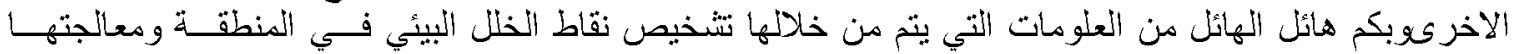

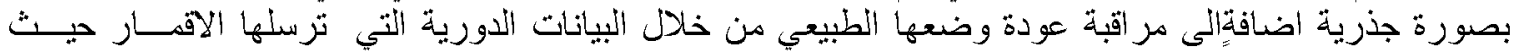

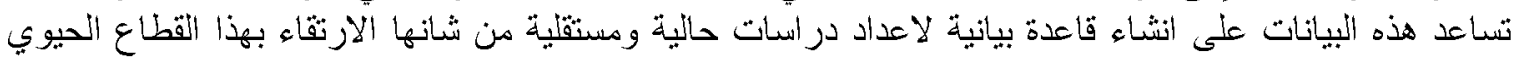

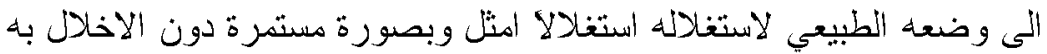

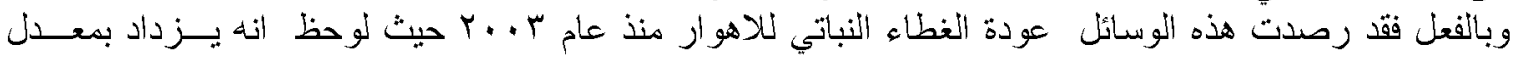

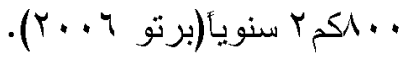

\section{الإيانات المستخدمة في الارباسة}

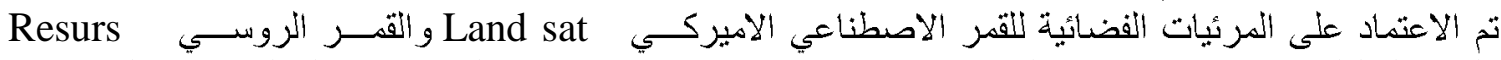

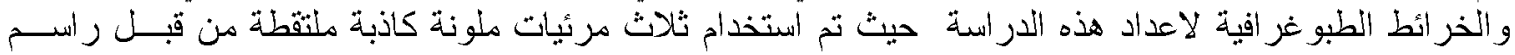

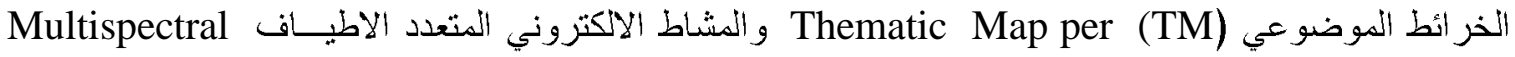
multi -spectral optical mechanical radiometer with conical ( MSU-SK) و Scanner System

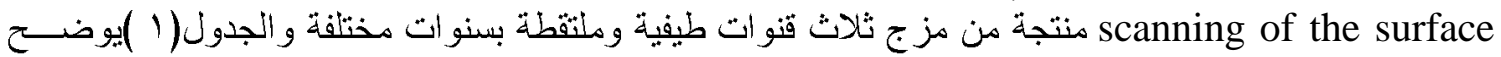

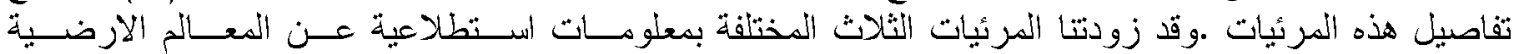

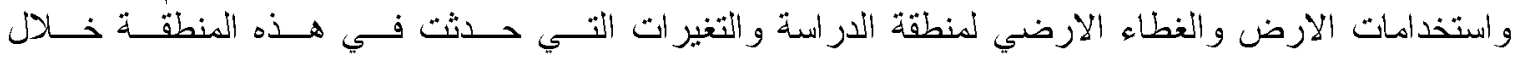

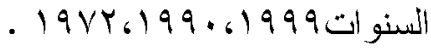


الجدول (1 ) المرئيات الفضائية المستخدمة في الدراسة

\begin{tabular}{|c|c|c|c|c|c|}
\hline اتثاريخ & القثوات & المقياس & المتحسس & القمر الصناعي & نوع المرئية الفضـية \\
\hline 1972 & 4-2-1 & 170000:1 & MSS & Landsat & ملونة كاذبة \\
\hline 1990 & 4-3-2 & 170000:1 & TM & Landsat & ملونة كاذبة \\
\hline 1999 & 4-3-2 & 170000:1 & MSU-SK & Resurs & ملونتة كاذبة \\
\hline
\end{tabular}

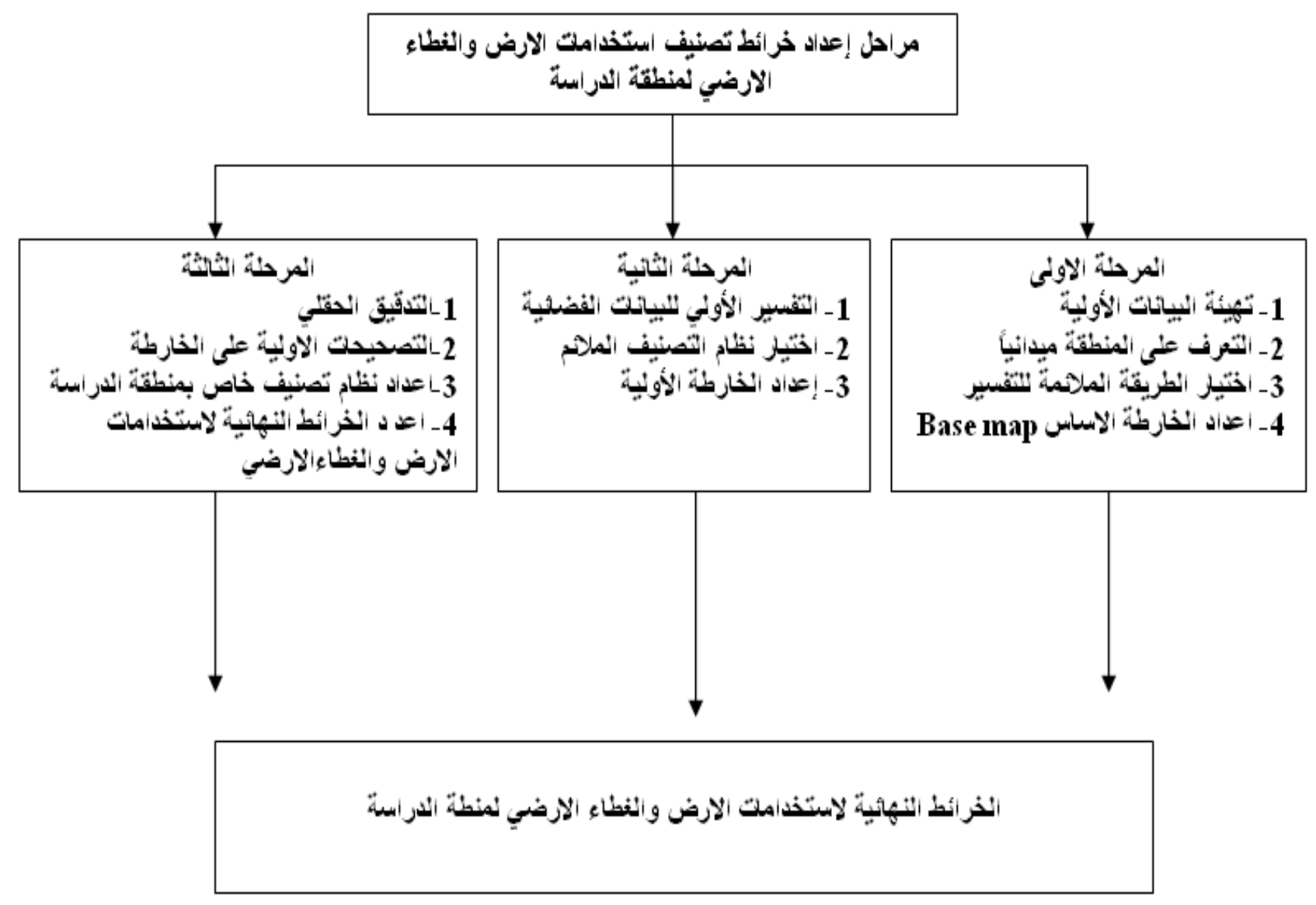

الثكل (1 ) يوضح مراحل اعداد خارطة تصنيف استخذامات الارض و النطاء الارضي لمنطقة الدراسة 


\section{تصنيف استخدامات الأرض والغطاء الأرضى لمنطقة الدراسة}

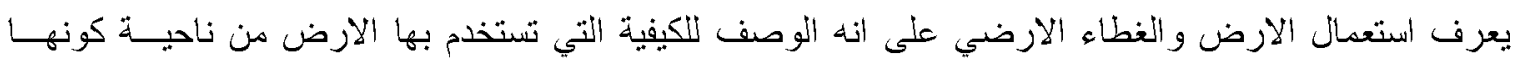

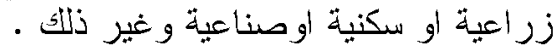

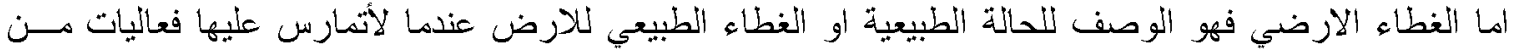

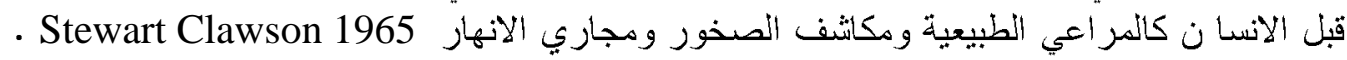

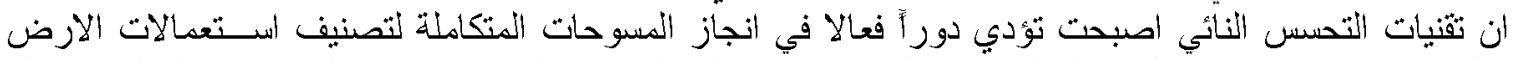

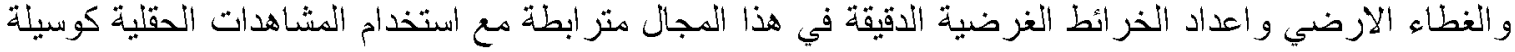

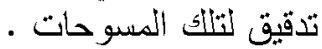

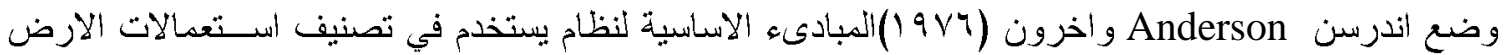

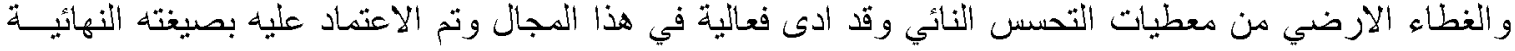

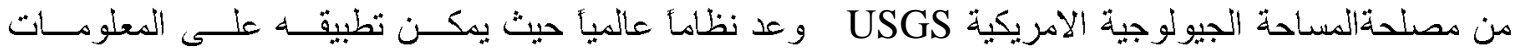

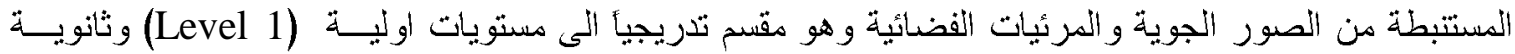

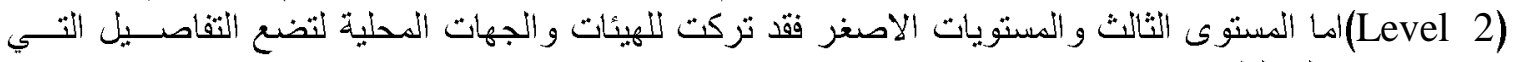
يناسب بيئاتها المحلية ان الهدف من تصنيف استعمالات الارض وضئ الغطاء الازرضي وتمثيلها على شكل خارطة غرضية لأعداد جــداول

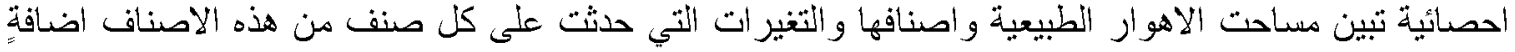

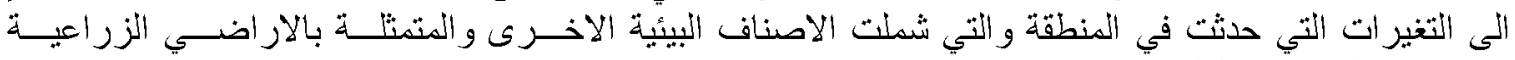

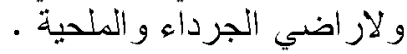

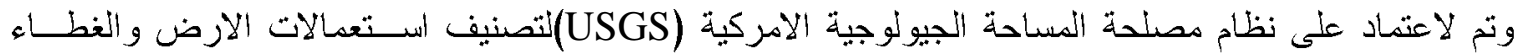

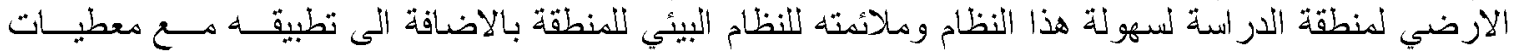

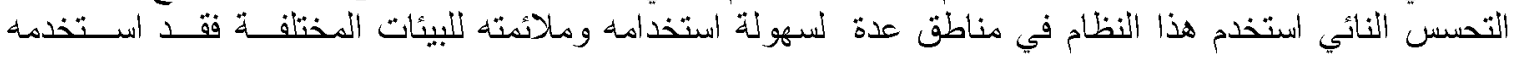
بالم Souch

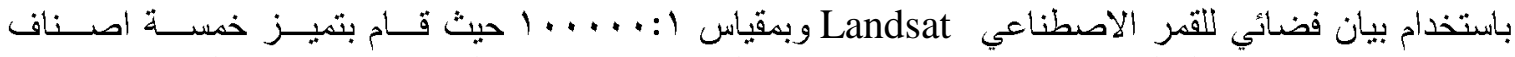

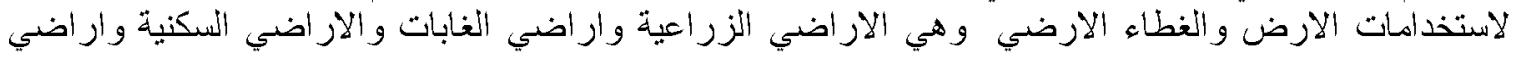

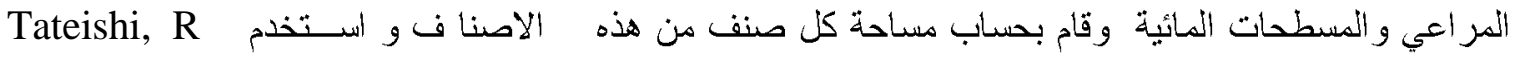

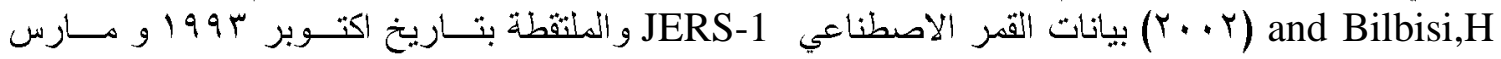
1990 190 - Supervised Classification

\section{خرائط استخدامات الارض وضوالغطاء الارضي لمنطقة الأراسة}

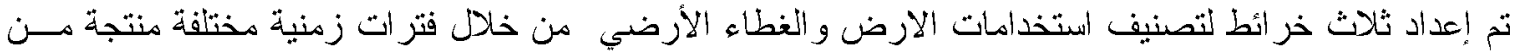

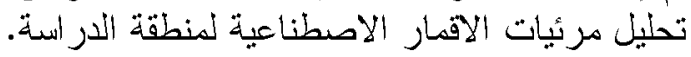

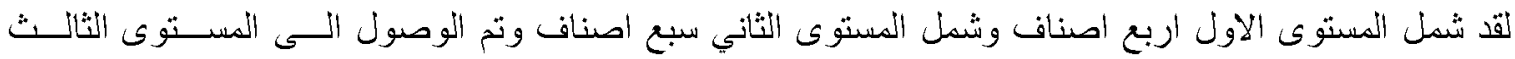

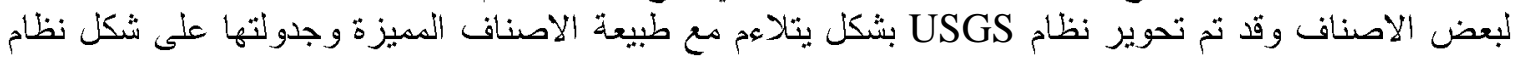

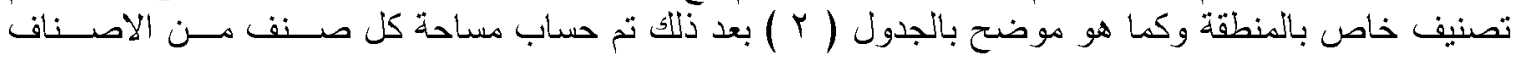

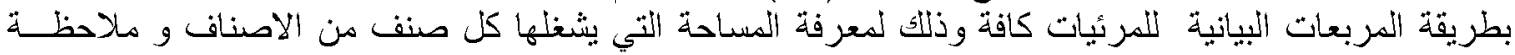

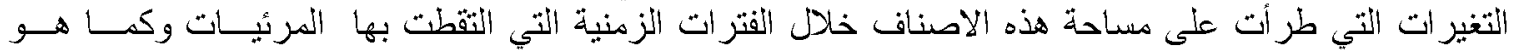

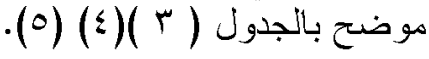


الجدول (ץ ) نظام تصنيف استخدامات الارض والغطاء الارضي لمنظقة الدر اسة والمعد بحسب نظام Anderson

\begin{tabular}{|c|c|c|}
\hline المستوى الثُشث & المستوى الثاني & المستوى الأول \\
\hline - & 11 مناطق سكثية" & الاراضي الحضرية \\
\hline - & 22 بستثين & الاراضي الززاعية \\
\hline - & 23|راضي المحاصيل المرويـة & \\
\hline 511 & 51 انههر 51 & الثياد \\
\hline 512 نهر دجلةّة & & \\
\hline 513 شط العرب & & \\
\hline 521 & & \\
\hline 522 مياد وغطاء نباتي قُليل الكثافَّة & & \\
\hline 523 مياد وغطاء نباتي كثيف & & \\
\hline 711 مجفظة اصطثاعيًاً & 71 الاراضي الملحية الجافقة & 7 الاراضي الجرداء \\
\hline 712 منية جافة طييعية & & \\
\hline & 77 اراضي جرداء مختمطة & \\
\hline
\end{tabular}

الجدول (r) المساحة التي يشظلها كل صنف من اصناف استخدامات الارض والغطاء الارضي لمنطقة الدراسة

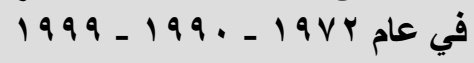

\begin{tabular}{|c|c|c|c|}
\hline انمسشتة كث 2 & ألمساحتّ كم 2 & انُمسشتة كم 1972 & أسم ألصثف \\
\hline 5.057 & $4 \times 335$ & 2,89 & المثناطث السكثية \\
\hline 8.67 & 9.392 & $17 \cdot 34$ & بساتيث \\
\hline 676.26 & 491 ، 3 & 247.095 & أرأضي أمحاصيل أنمروية \\
\hline- & - & - & نـهر ألفرات \\
\hline - & - & - & نَهر دجلة \\
\hline- & - & - & شيط انعرب \\
\hline 2.89 & $10 \cdot 115$ & $92 \cdot 48$ & مياد ثقط \\
\hline 266732 & 119.935 & 234.09 & 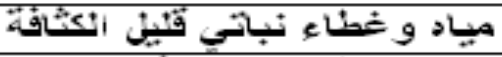 \\
\hline $84: 81$ & 184.96 & 236.98 & مياد و ثطفاء ثبنتي كثيفت \\
\hline 239.87 & 69.36 & $\mathbf{0}$ & 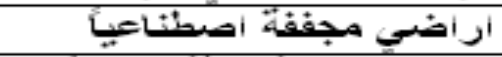 \\
\hline 8.67 & 9.32 & $10 \cdot 115$ & 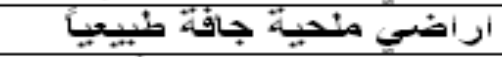 \\
\hline $1046 \cdot 18$ & 1199635 & $1257 \cdot 15$ & ارأضسي جردأع مختشطية \\
\hline $2098 \cdot 15$ & $2098 \cdot 15$ & 2098,15 & الثمساحتة انكثيّة \\
\hline
\end{tabular}

_ لم تحسب مساحتها لانها تظهر بشكل خطي تضدن نظام تصنيف استخداما ت الارض و الغطاء الارضي لمنطقة الدر استة عدة أصناف التي تم الوصول الــى

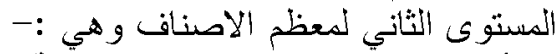
1-أزراضي الصنف (1)المر اكز الحضرية (السكنية) 
لم يتم تمييز هذا الصنف بسهولة لقلة دقة البيانات الفضائية وتم تحديدها من خلال الخر ائط الطبو غر افية الخاصــة

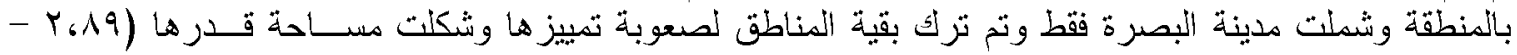

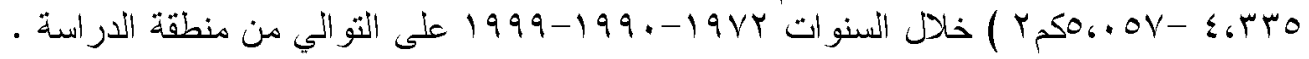

$$
\begin{aligned}
& \text { rأراضي الصنف (r)الأز اضي الزراعية } \\
& \text { وشملت:- } \\
& \text { اولاً: الصنف (r (r) البساتين: }
\end{aligned}
$$

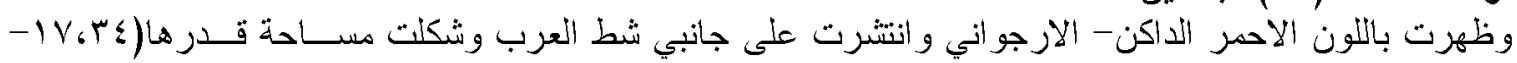

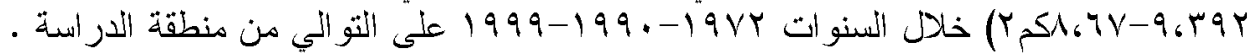

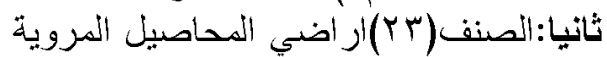

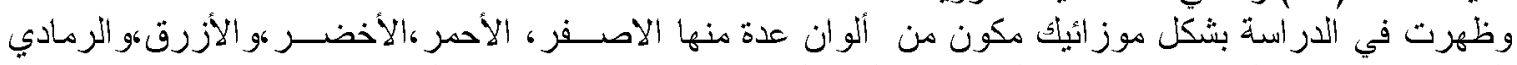

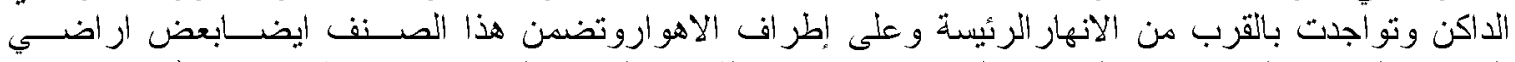

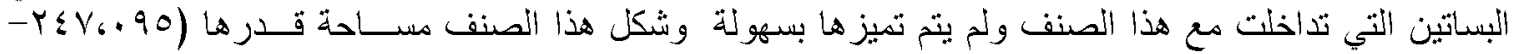

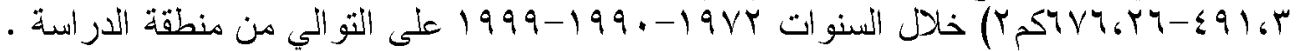

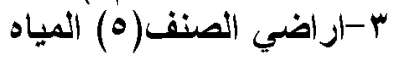

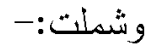

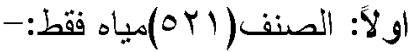

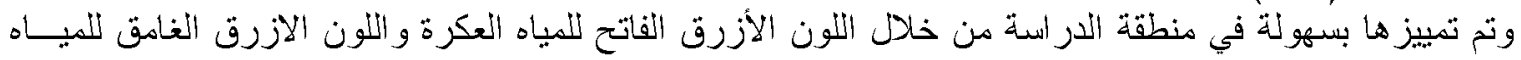

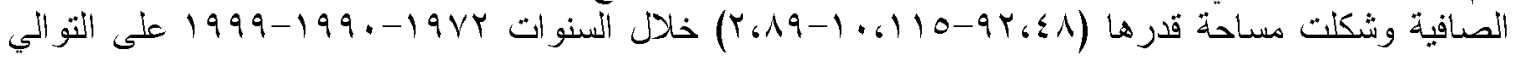

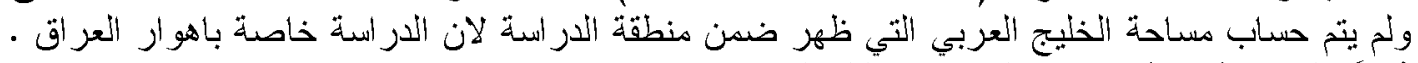

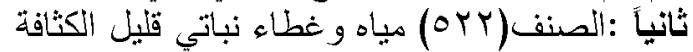

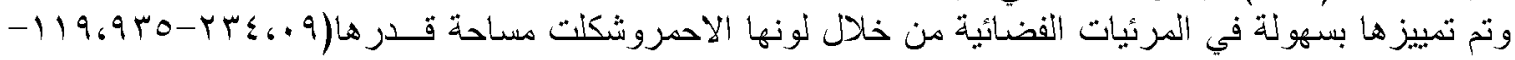

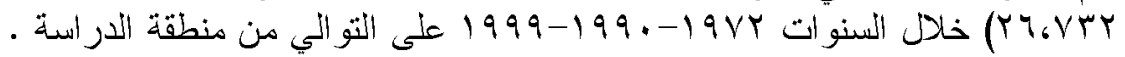

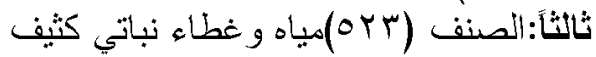

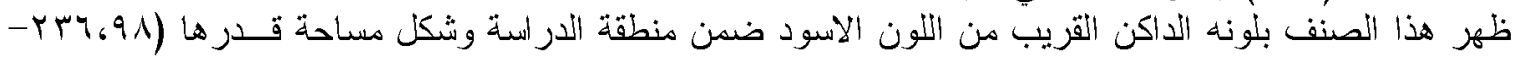

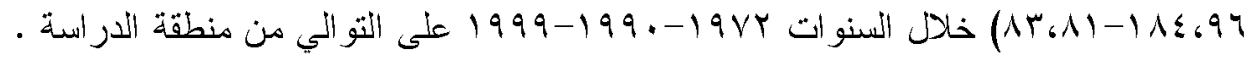

$$
\begin{aligned}
& \text { צ-اراضي الصنف (V) الأراضي الجرداء } \\
& \text { و وشملت:- }
\end{aligned}
$$

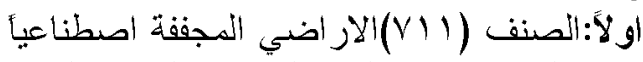

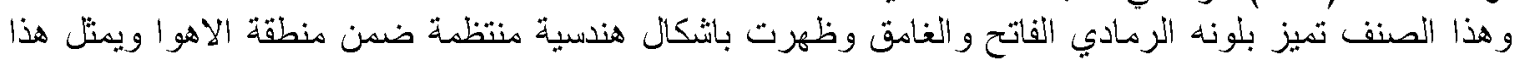

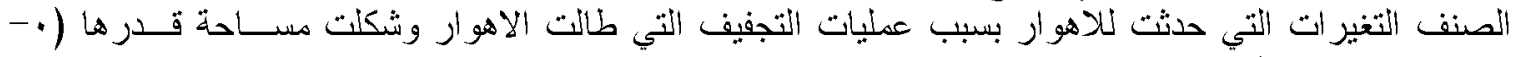

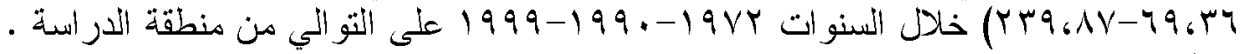

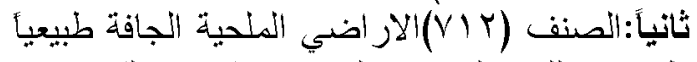

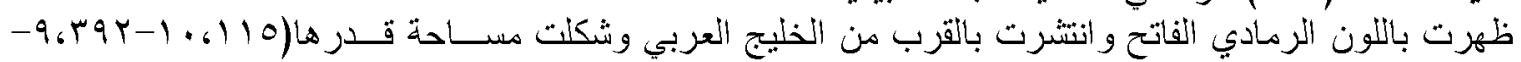

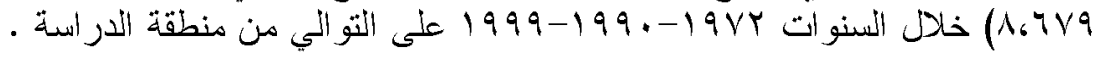

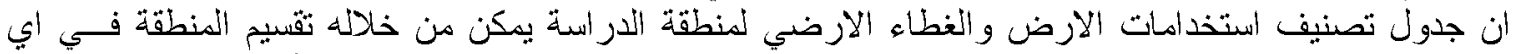

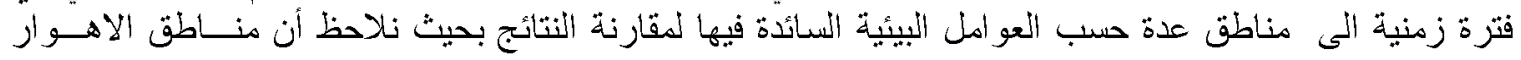

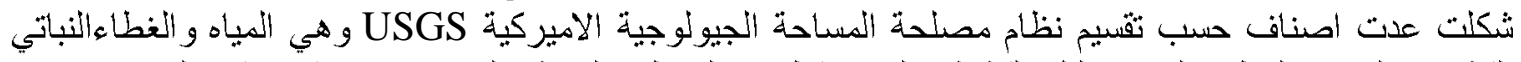

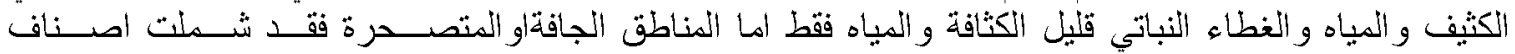

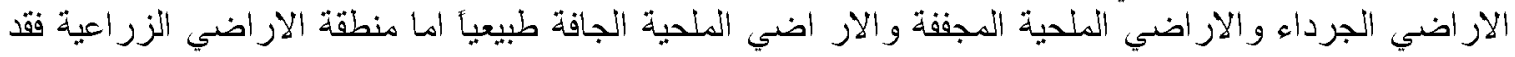

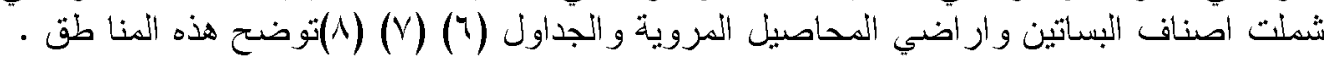




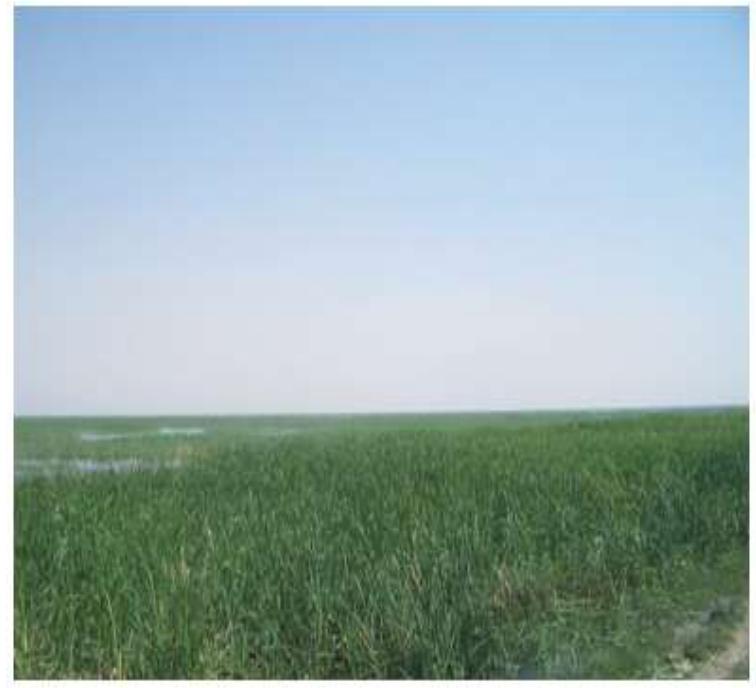

الصورة (ץ) توضح الصنف ب ه المياه والغطاء النباتي الكثيف

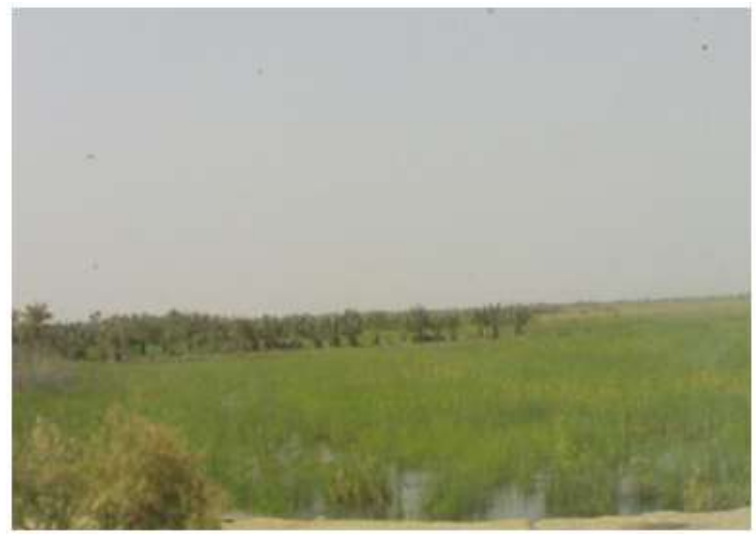

الصورة (0) توضح تذاخل صنف البساتين مع الاهوار

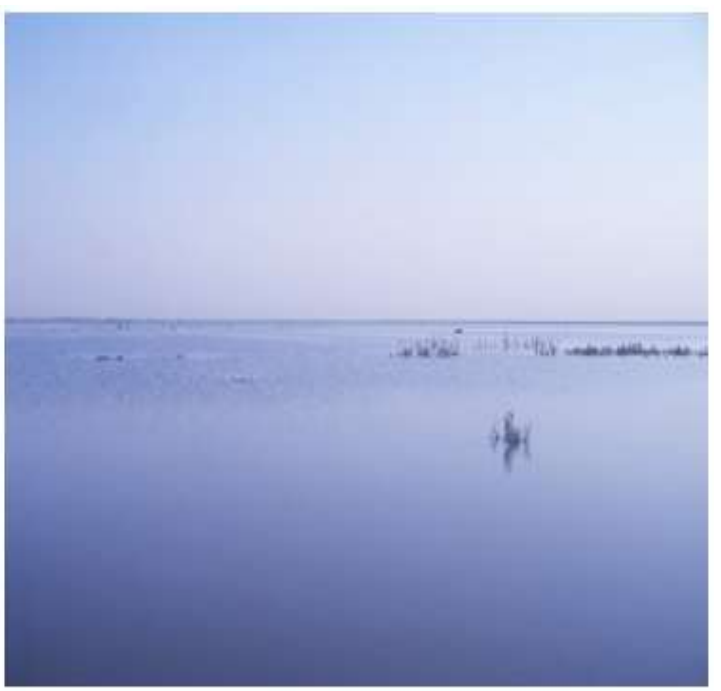

الصورة (1) توضح الصنف ال به المياه فقط

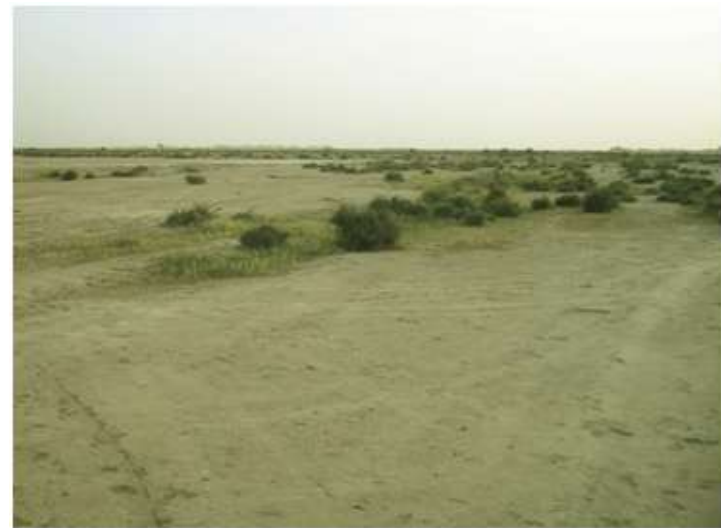

الصورة (ع ) توضح الصنف ا V V الأراضي المجففة اصطناعي

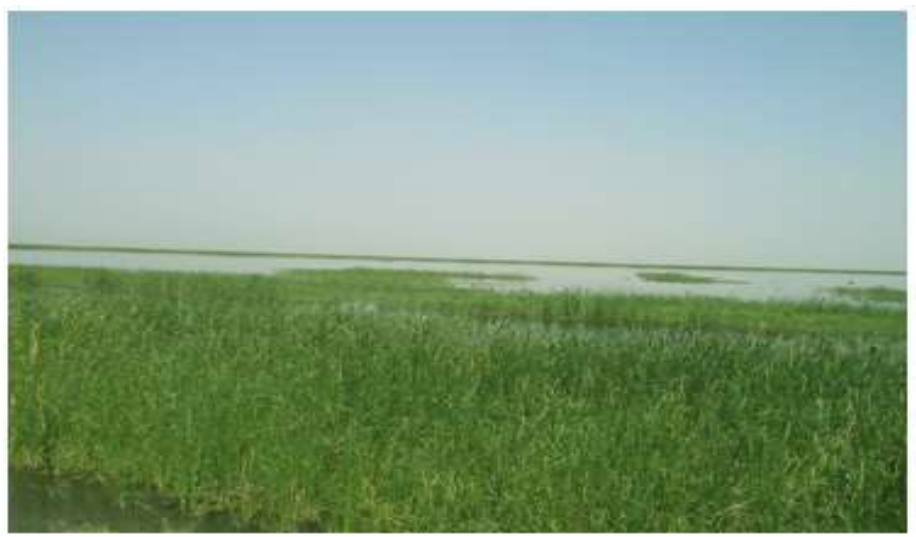

الصورة (r) توضح الصنف r r ه المياه والغطاء النباتي قليل الكثافة 
الجدول (7 ) يوضح المناطق البيئية الرئيسية الثلاث لمنطقة الدراسة حسب اصنافها ومساحتها في عام Y Y

\begin{tabular}{|c|c|c|c|}
\hline ألمساحة أكلية" & مساحة" التصنف & |أصناف الثي شمتثها & المثاطق \\
\hline & $2592 \cdot 48$ & مياد & منطقة الاهوار \\
\hline & $2 \$ 236.98$ & مياد وغطناء نبانتي كثيف & \\
\hline $2 \lessgtr 563 ، 55$ & $25234 ، 09$ & 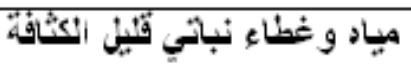 & \\
\hline & $2 \leq 1257 \cdot 15$ & الار اضبي ألجرداء & منطقة" الاراضشي أجافَّة \\
\hline & $2510 \cdot 115$ & 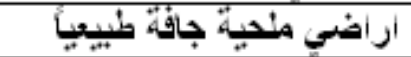 & \\
\hline $2 \lessgtr 1267.265$ & - & أراضسي مججفة:ة & \\
\hline & $2 \leqslant 17,34$ & بساثتيث & منطقة" الاراضي أزتراعبة \\
\hline $25264 \cdot 435$ & $2 \leqslant 247,095$ & محاصيل مروية" & \\
\hline
\end{tabular}

الجدول (V ) يوضح المناطق البيئية الرئيسية الثلاث لمنظقة الدراسة حسب اصنافها ومساحتها في عام • 99

\begin{tabular}{|c|c|c|c|}
\hline أمساحة" انكيبة & مساحثة الصثثف & 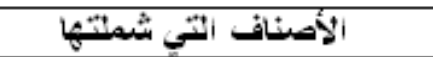 & ألمناطُق \\
\hline & $2 \$ 10 \times 115$ & مياد & منطقة الاهو ار \\
\hline & $2 \lessgtr 184 ، 96$ & مياد و غطناء نبانتي گثيف & \\
\hline $2 \Im 315 ، 01$ & $2 \lessgtr 119 ، 935$ & 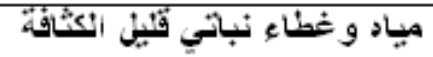 & \\
\hline & 251199635 & الاراضي ألجرداء & منطقة الاراضسي أجافَّة \\
\hline & 2.59 .392 & أراضسي منحية جافة طنيعيًاً & \\
\hline $2, \$ 1278 \cdot 10$ & $2569 ، 36$ & ار اضضي مججفقة & \\
\hline & 2596392 & بستئيث & منطقة الاراضسي أتزراعبة \\
\hline $2 \lessgtr 500 \cdot 69$ & $2 \leq 491 \cdot 3$ & محاصبيل مروبية & \\
\hline
\end{tabular}

الجدول ( ^) يوضح المناطق البيئية الرئيسية الثلاث لمنطقة الدراسة حسب اصنافها ومساحتها في عام 999

\begin{tabular}{|c|c|c|c|}
\hline أنمساحة أنعبة" & مساحة" انصنفة & أأصناف أثي شتثيا & ألمناطُق \\
\hline & $2 \leq 2 \cdot 89$ & مياد & منطقةُ الاهوار \\
\hline & $2-53 ، 81$ & مياد وغطاء ثباثي كثيف & \\
\hline $2 \leqslant 113 ، 432$ & 2526.732 & 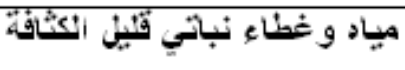 & \\
\hline & $2 \div 1046 \cdot 18$ & ألار أضب ألجرداء & منطفة الاراضشي ألجاقة \\
\hline & 258.67 & 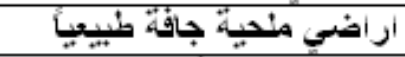 & \\
\hline $2 \$ 1294 ، 54$ & $2 \lessgtr 239 ، 87$ & أراضي مجنفة" & \\
\hline & 258.67 & بسانيثن & منطقة الاراضي أزراعية \\
\hline $25684 ، 93$ & $25676 \cdot 26$ & محاصبل مروبة" & \\
\hline
\end{tabular}

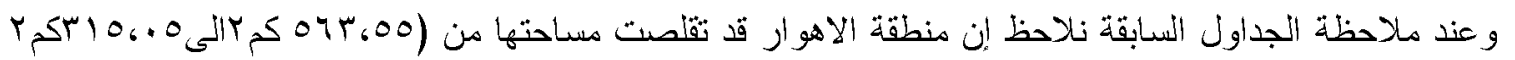

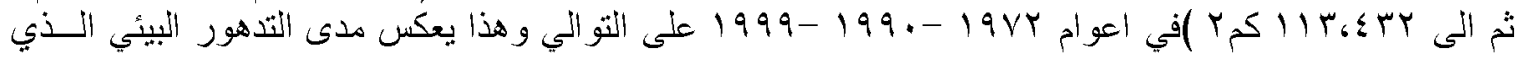




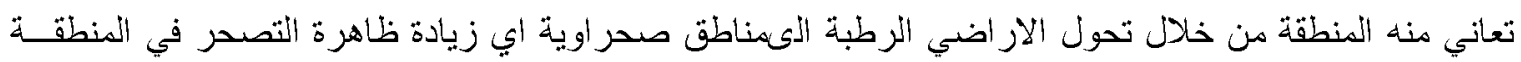

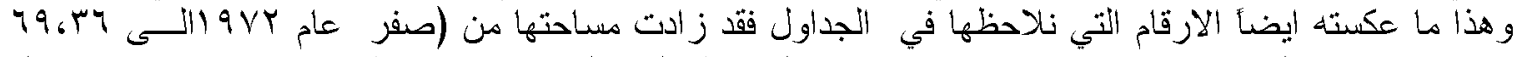

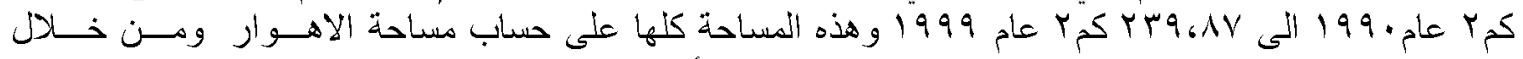

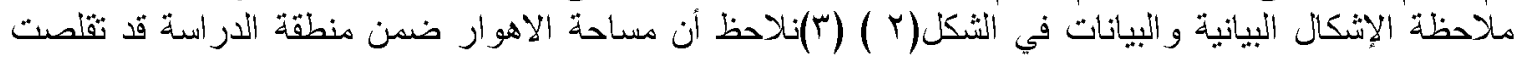

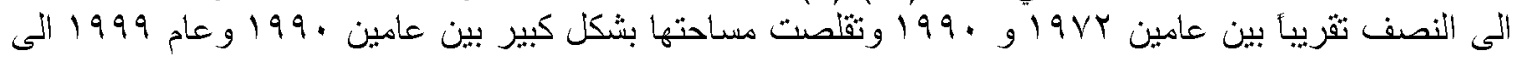
حو الي ثلثي مساحتها تثريبا

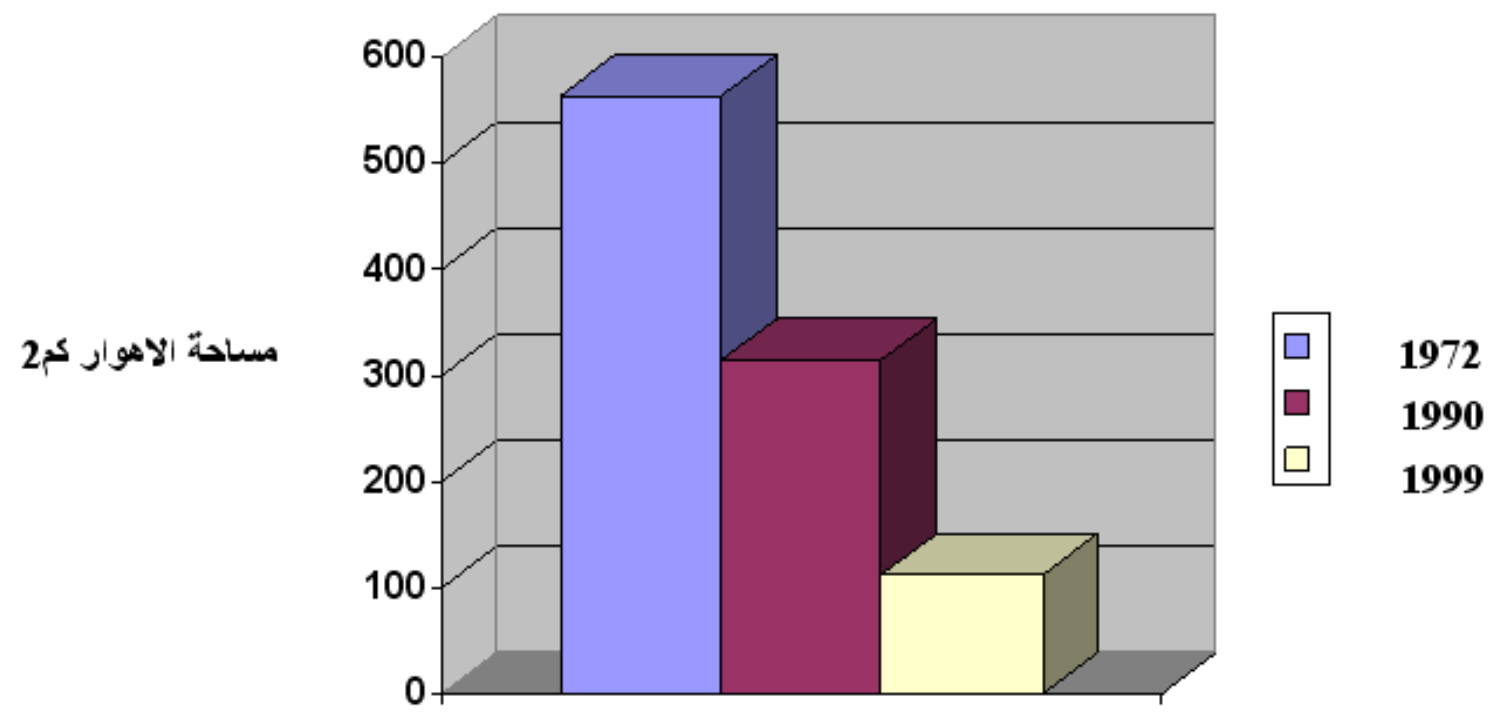

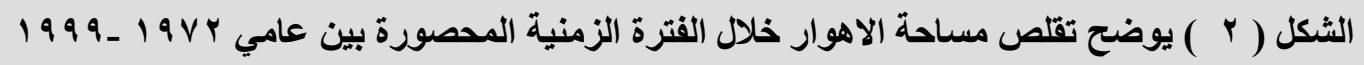

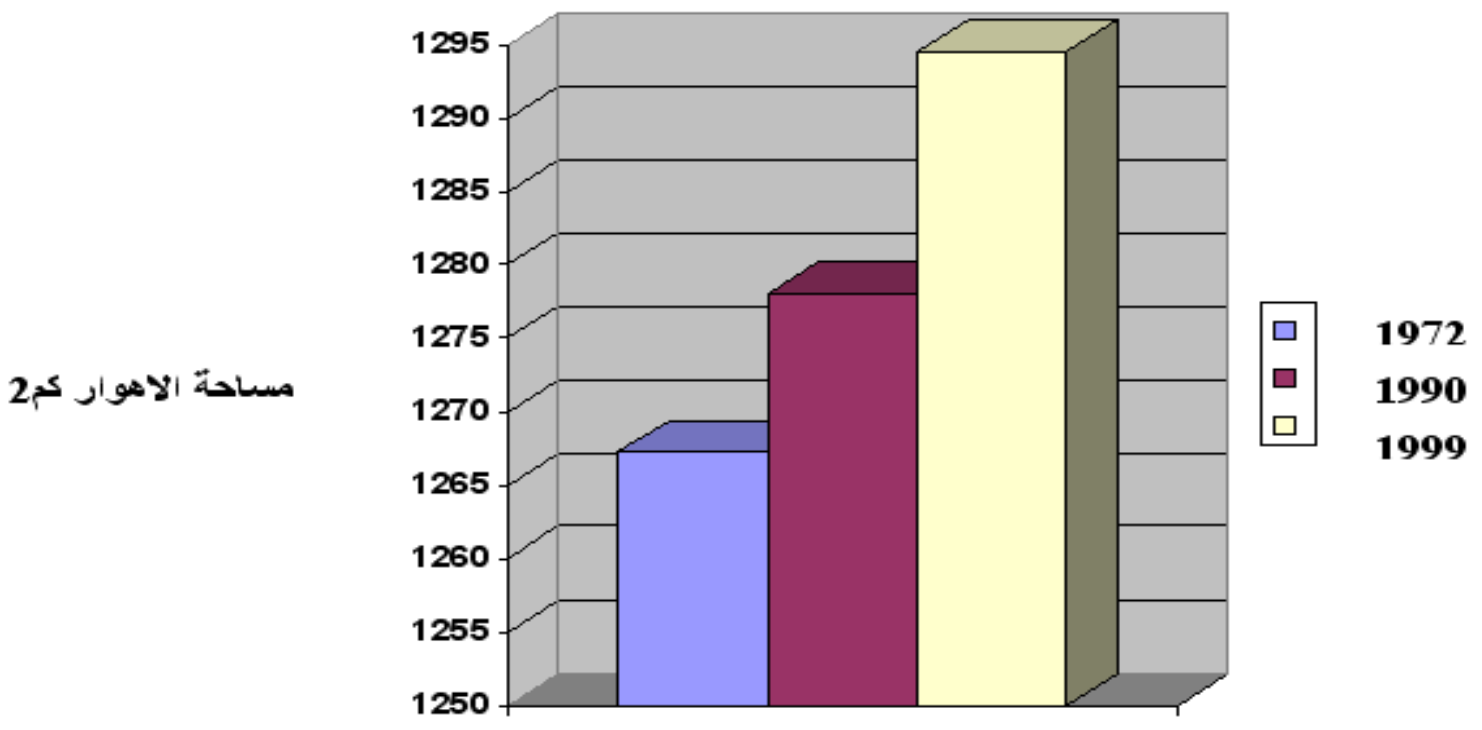

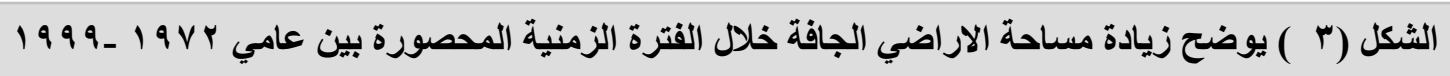

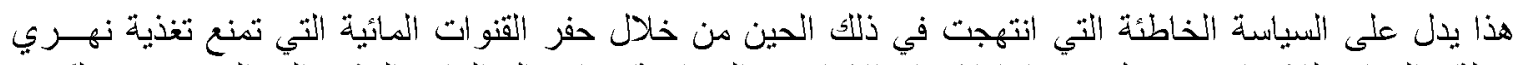

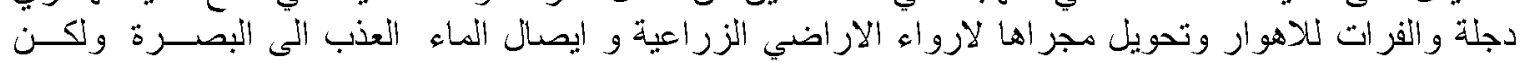




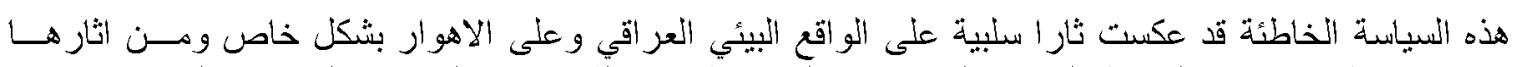

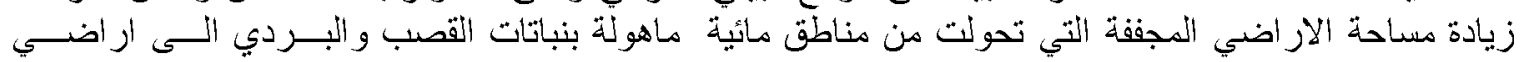

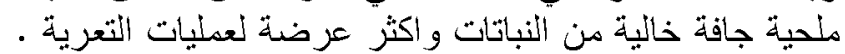

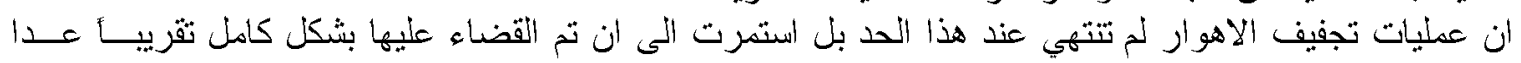

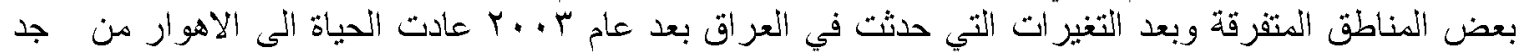

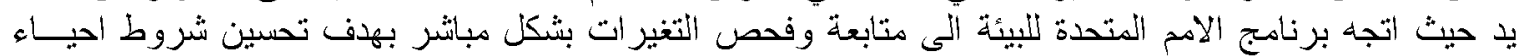

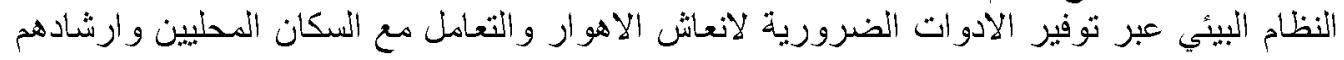
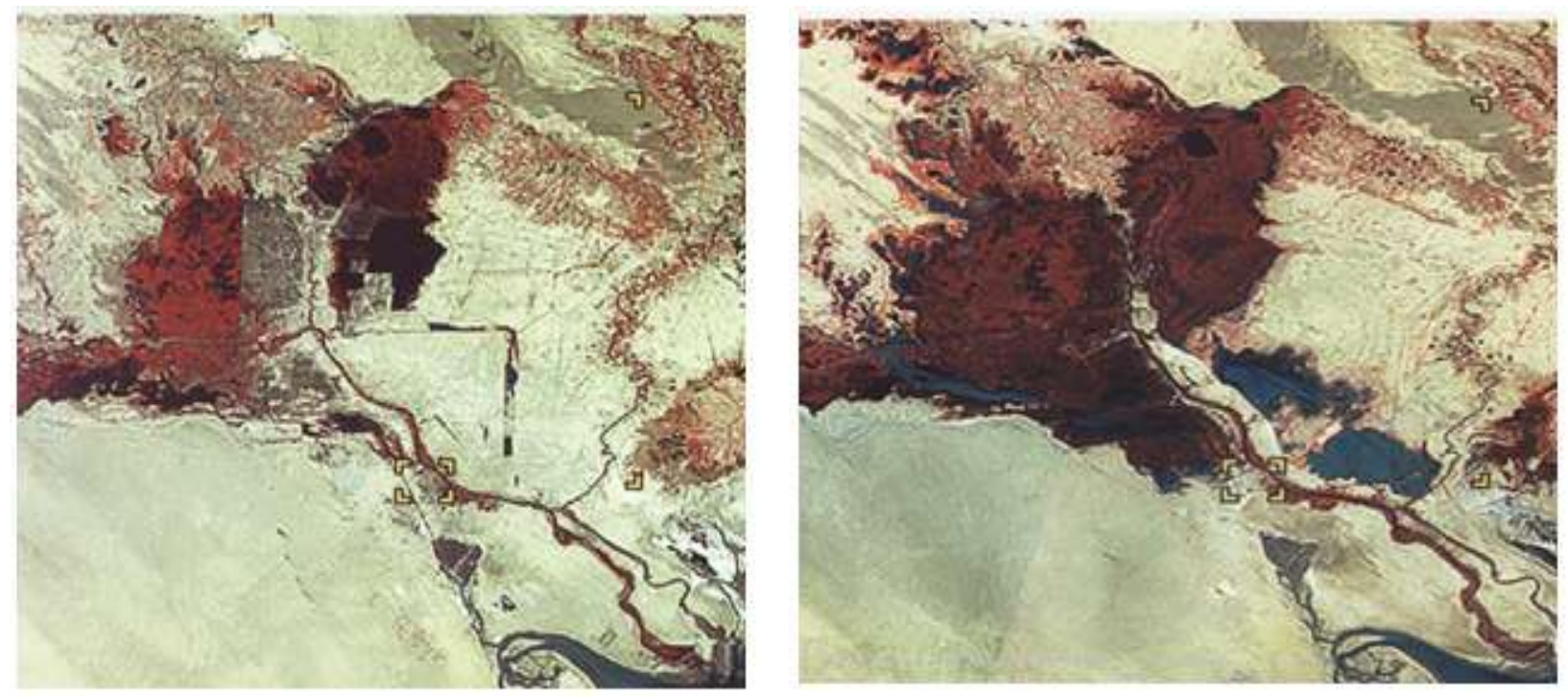

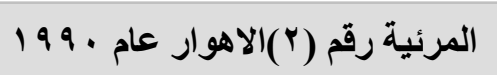

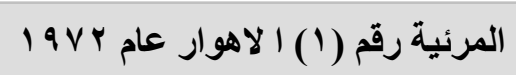

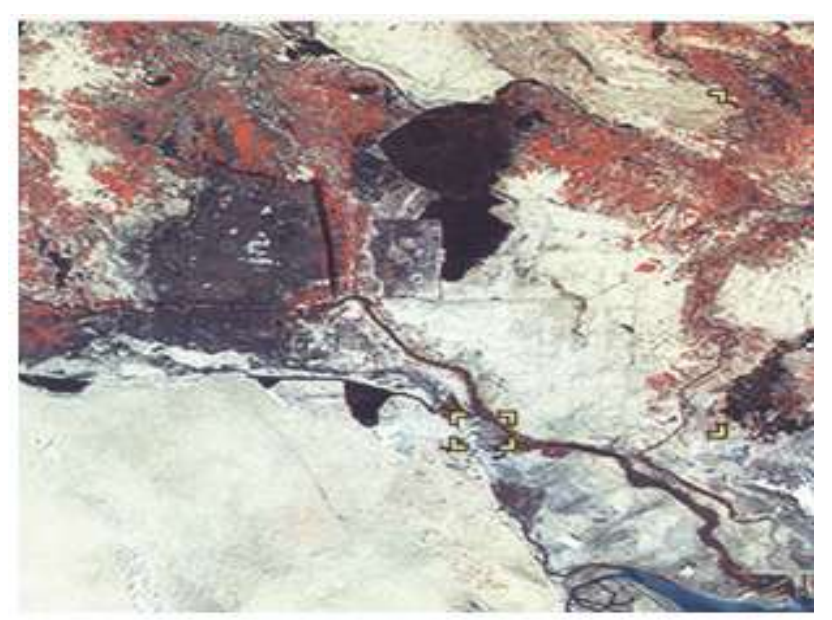

المرئية رقم ("آ) الاهوار عام 1999 

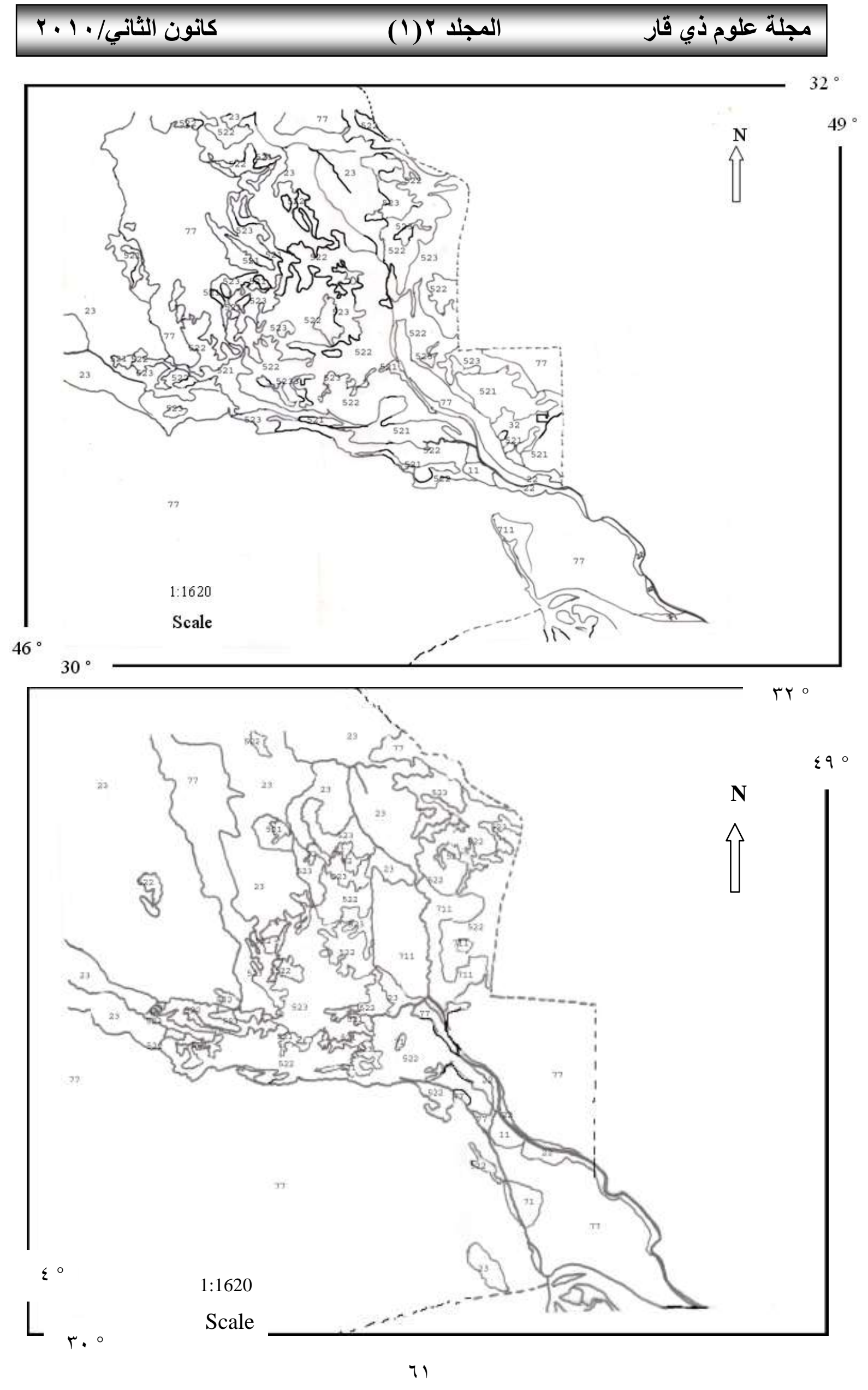


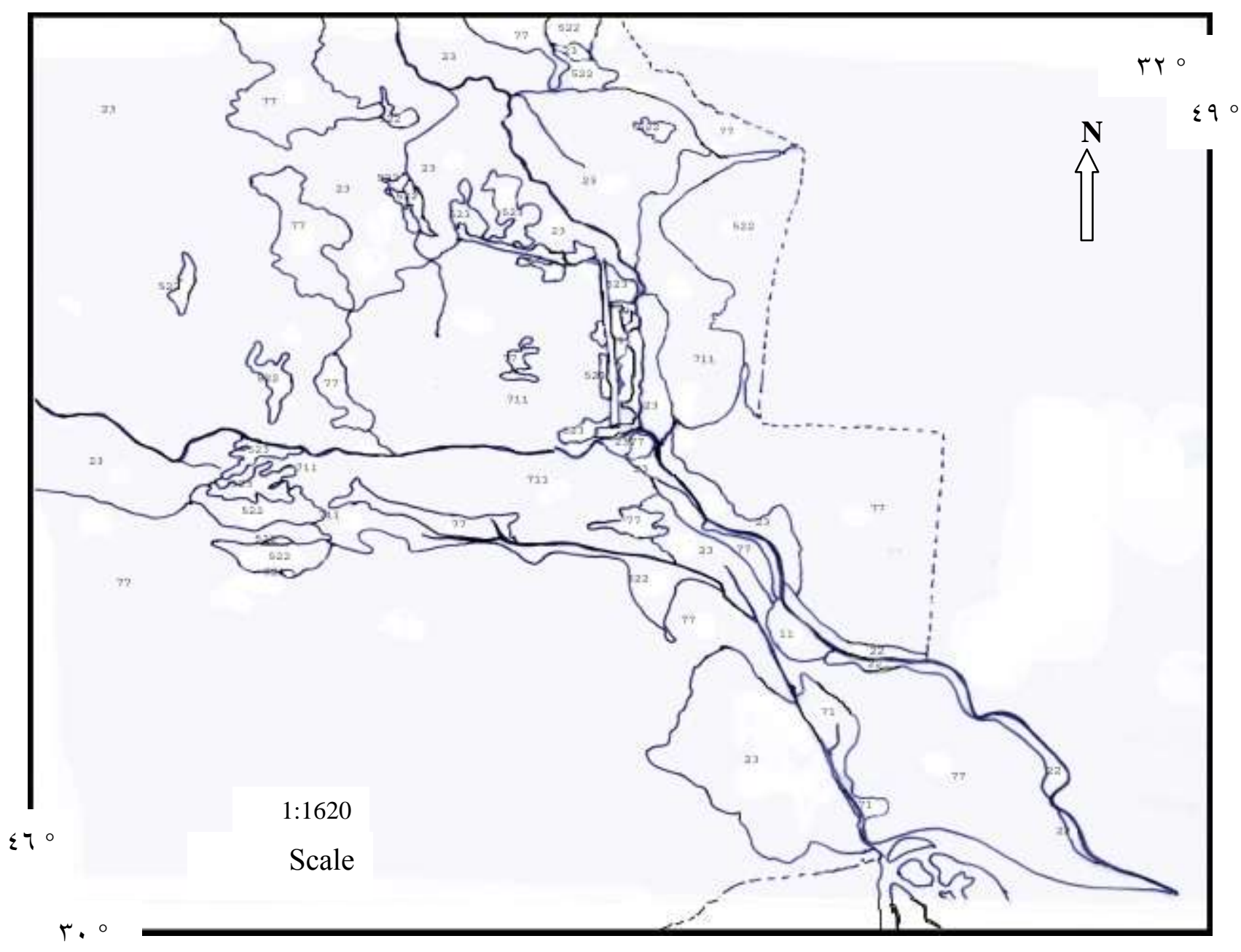

\section{Land-use and land-cover map on study area as interpret from land sat and rouser satellite in 1972-1990-1999}

3-Anderson, I.R. Hardy, E, E, Roach cover witmer, R, E (1976) A land use and land cover classification system for the use with remote sensor data geological survey professional paper 964. U.S. Government printing office Washington, D.C.28p,

4-Clawson, M. and Stewart, C.I. (1965): land use information, A critical survey of U.S. statistics including possibilities for greater uniformity: Baltimore, Md, the johns Hopkins press for the future, INC, 402p.
References

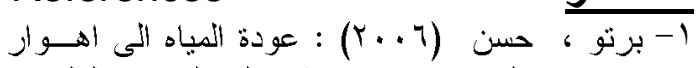

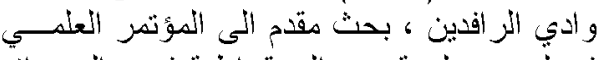

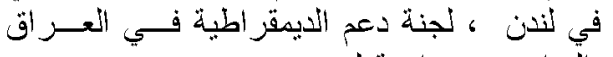

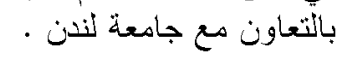

2- AL-bilbisi, Hussam and tateishi, Ryatero (2002) A study on land use |cover classification with textural analysis using multi-temporal JERS-1(SAR)

$\mathrm{L}-\mathrm{Band}$ in arid and semi areas(A case Study in northern Jordan )center for environmental remote sensing (CERS)chiba University . Japan 
interpretation , Iranian remote sensing center, Tehran, Iran.
5-Soroush , K.A.(1999) \land cover mapping of central water shed of Iran

Areabased on satellite data

\title{
USE OF REMOTE SENSING DATA IN MONITORING THE ENVIRONTMENT CHANGES IN SOUTHREN IRAQ MARSHLAND
}

\section{ALI FADHEL HASSAN AL-NAELLY \\ FACULTY OF AGRICALTUER-ALMUTHANA UNVERCITY}

\begin{abstract}
This study has dealt with assessing reality of marshland through monitoring the changes that took place from 1999-1972 and for a zone falling between(32-30) northern and (49-46)eastern which has constituted an area of $2098 \mathrm{~km} 2$ through preparing thematic maps and by depending on three false colored satellite image namely, landsat and resurs satellite taken in 1972-1990-1999 .

After interpreting the satellite data of preparing these maps for the land use and land cover depending on the USGS system initiated by Anderson 1976, it has been found out that marshland is undergoing a constant deterioration as a result of the decrease of its area as a result of the process of drying practiced by the former regain by then. The area of marshland has been reduced $563.55 \mathrm{~km} 2$ in 1972 to $315.01 \mathrm{~km} 2$ in 1990 until it became $113.43 \mathrm{~km} 2$ in 1999 , the area of dried lands from zone in 1972 to $69.36 \mathrm{~km} 2$ in 1990 moving upwards to reach 239.87 in 1999 therefore this has lead to the increase of dried land which includes arid land the natural-dried salty arid land and the man wade arid dried land from $1267.26 \mathrm{~km} 2$ in 1972 to $1287.1 \mathrm{~km} 2$ in 1990 and to $1294.54 \mathrm{~km} 2$ in 1999 . The study points to the clear deterioration the marsh land are undergoing in southern Iraq which has been wade clear by the findings of study which has covered a considerable part of marsh land in southern Iraq .
\end{abstract}

